\title{
Identification of retrograde peristalsis determines the afferent limb during double- balloon ERCP: the tidal wave sign
}

Double-balloon endoscopy is used in endoscopic retrograde cholangiopancreatography (ERCP) in patients with surgically altered gastrointestinal anatomy [1]. In this procedure, it is difficult to identify the afferent limb of a Roux-en-Y anastomosis; therefore, intraluminal injection of indigo carmine and carbon dioxide enterography has been used [2, 3]. We report a novel method to identify the afferent limb.

The endoscope is inserted into the Rouxen-Y site without an antispasmodic agent. Retrograde peristalsis is detected in the afferent limb and antegrade peristalsis in the efferent limb ( Fig.1 a). The finding of intestinal mucosal involvement in the attachment can be seen in retrograde peristalsis ( $>$ Fig. $\mathbf{1} \mathbf{b}$ ), whereas this finding cannot be seen in

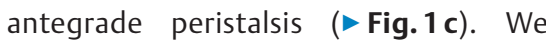
called this the "tidal wave sign"; the limb with this sign is the afferent limb ( $\vee$ Fig. 2), and the limb without it is the efferent limb ( $\triangleright$ Fig. 3 ).

- Video 1 shows the findings in a typical patient. At the Roux-en-Y site, one lumen was judged to have antegrade peristalsis; the intestinal mucosa was not involved in the attachment. We evaluated this lumen as negative for the tidal wave sign and identified it as the efferent limb. The other lumen had retrograde peristalsis and the intestinal mucosa was involved in the attachment. We evaluated this lumen as positive for the "tidal wave sign" and identified it as the afferent limb.

We analyzed consecutive cases between January 2013 and August 2018; this technique was used after March 2016. The tidal wave sign was evaluated prospectively in 31 examinations involving 17 patients with a Roux-en-Y anastomosis. In 26/31 examinations (83.9\%), the afferent limb was accurately identified, while accuracy without this technique was $50 \%$ in 10 cases. The accuracy when using this sign was significantly higher

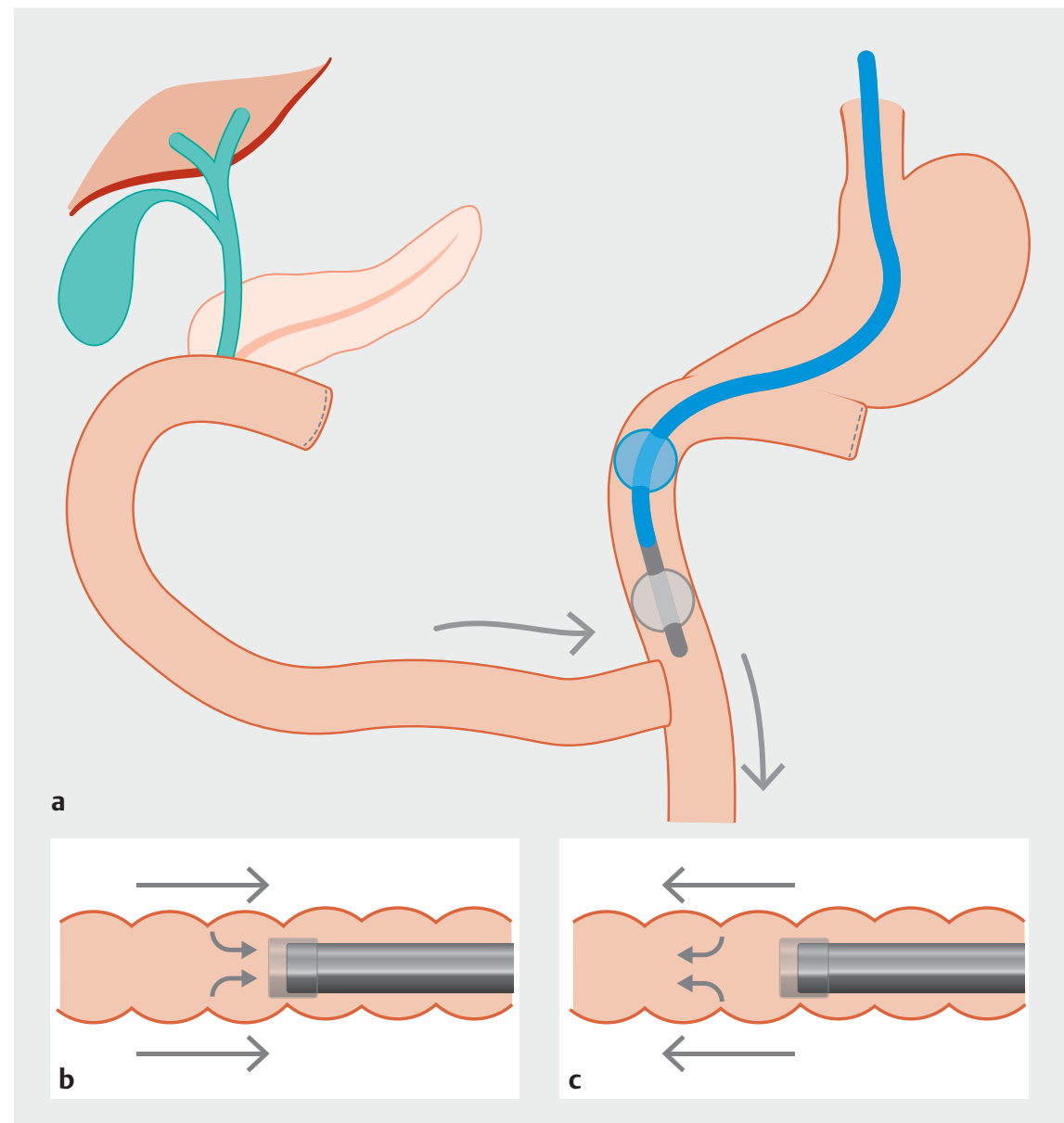

- Fig. 1 Schematics of a Roux-en-Y site showing that: a retrograde peristalsis is found in the afferent limb, while antegrade peristalsis is found in the efferent limb; b intestinal mucosal involvement in the attachment can be found in retrograde peristalsis; $\mathbf{c}$ no intestinal mucosal involvement in the attachment is found in antegrade peristalsis.
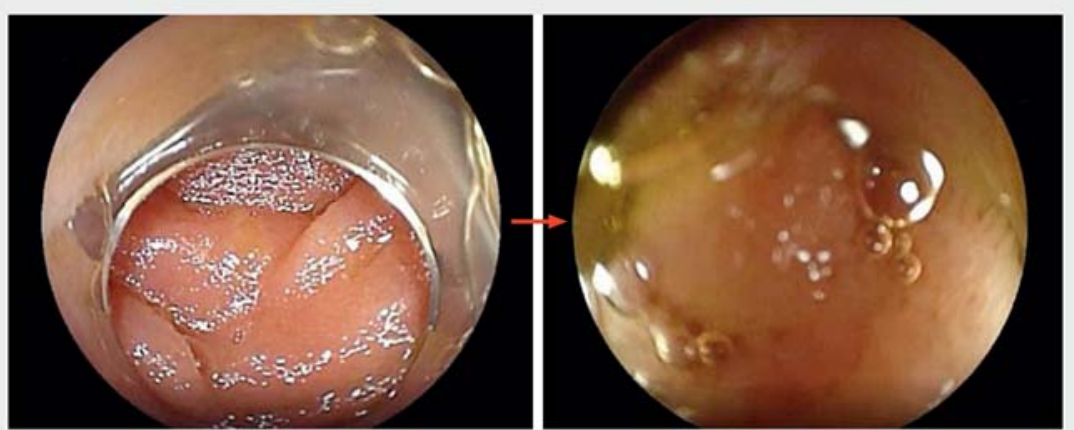

- Fig. 2 Endoscopic views showing a positive tidal wave sign, meaning this limb is identified as the afferent one. 

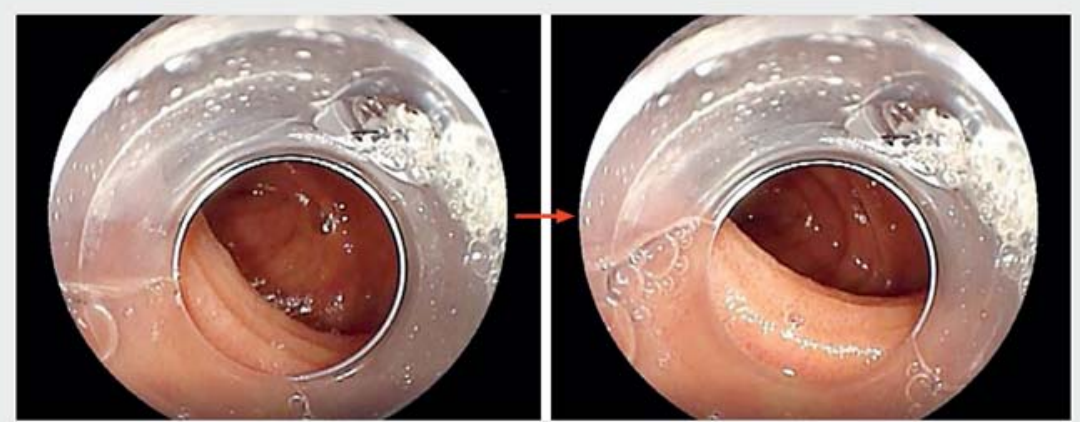

- Fig. 3 Endoscopic views showing no evidence of the tidal wave sign, meaning this limb is identified as the efferent one.

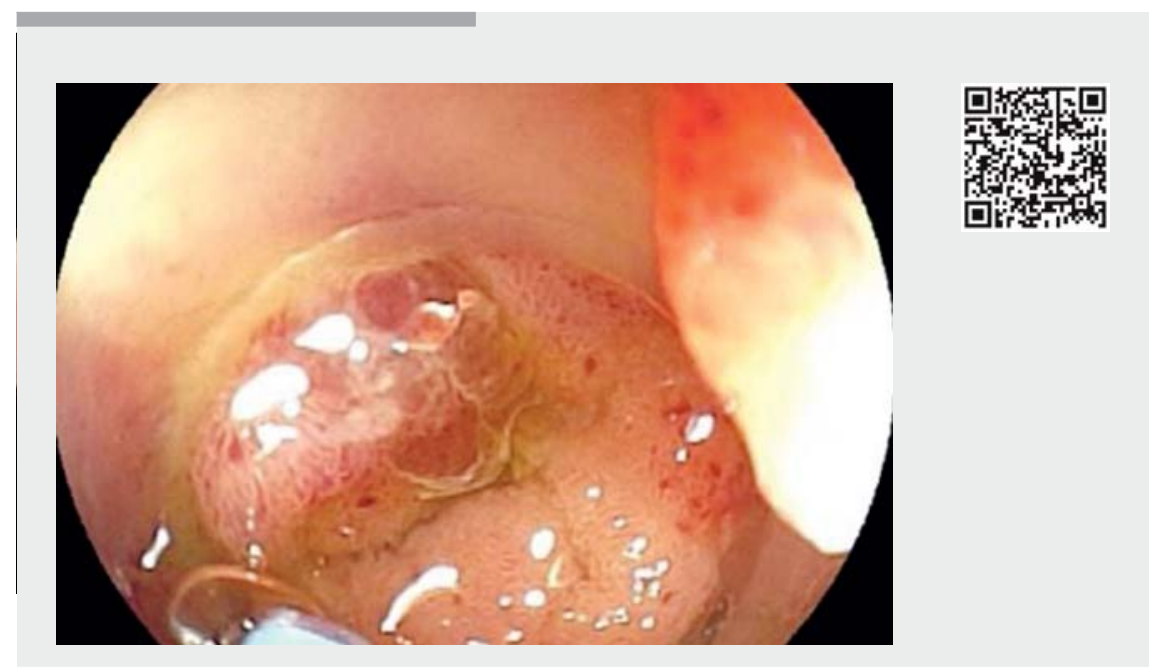

$\checkmark$ Video 1 Double-balloon endoscopy at the Roux-en-Y site, with one lumen evaluated as being negative for the tidal wave sign and the other as positive, which allowed them to be identified as the efferent and afferent limbs, respectively.

than when not using it $(P=0.009)$. This sign helps to determine the afferent limb during double-balloon ERCP in patients with a Roux-en-Y anastomosis.

Endoscopy_UCTN_Code_TTT_1AP_2AD

Competing interests
The authors

Tetsuya Iwasaki, Tomofumi Akasaka, Yuko Sakakibara, Shoichi Nakazuru, Hisashi Ishida, Eiji Mita

Department of Gastroenterology and Hepatology, National Hospital Organization Osaka National Hospital, Osaka, Japan
Corresponding author

\section{Tetsuya Iwasaki, MD}

Department of Gastroenterology and Hepatology, National Hospital Organization Osaka National Hospital, 2-1-14 Hoenzaka, Chuo-ku, Osaka 540-0006, Japan

Fax: +81-6-69463569

iwasaki@onh.go.jp

\section{References}

[1] Shimatani M, Matsushita M, Takaoka M et al. Effective 'short' double-balloon enteroscope for diagnostic and therapeutic ERCP in patients with altered gastrointestinal anatomy: a large case series. Endoscopy 2009; 41: $849-854$

[2] Yano $\mathrm{T}$, Hatanaka $\mathrm{H}$, Yamamoto $\mathrm{H}$ et al. Intraluminal injection of indigo carmine facilitates identification of the afferent limb during double-balloon ERCP. Endoscopy 2012; 44: E340-E341

[3] Fukuba N, Moriyama I, Ishihara S et al. Carbon dioxide enterography: a useful method for double-balloon enteroscopy-assisted ERCP. Endoscopy 2014; 46: E587 - E588

\section{Bibliography}

DOI https://doi.org/10.1055/a-0866-9226

Published online: 25.3.2019

Endoscopy 2019; 51: E141-E142

(c) Georg Thieme Verlag KG

Stuttgart · New York

ISSN 0013-726X

\section{ENDOSCOPY E-VIDEOS \\ https://eref.thieme.de/e-videos}

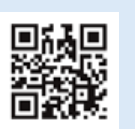

Endoscopy E-Videos is a free access online section, reporting on interesting cases and new techniques in gastroenterological endoscopy. All papers include a high quality video and all contributions are freely accessible online.

This section has its own submission website at https://mc.manuscriptcentral.com/e-videos 